\title{
ADAPTASI PERMAINAN TRADISIONAL MUL-MULAN KE DALAM PERANCANGAN GAME DESIGN DOCUMENT
}

\author{
Khamadi $^{1}$, Abi Senoprabowo ${ }^{2}$ \\ 1,2Program Studi Desain Komunikasi Visual, \\ Fakultas IImu Komputer, Universitas Dian Nuswantoro \\ khamadi@dsn.dinus.ac.id ${ }^{1}$, abiseno.p@gmail.com ${ }^{2}$
}

\begin{abstract}
Abstrak
Seperti halnya keberadaan permainan tradisional pada umumnya, Mul-mulan memiliki masalah yang sama yaitu telah tergeser oleh jenis permainan digital saat ini. Upaya membawa permainan Mul-mulan ke dalam permainan digital menjadi sangat memungkinkan melihat daya tarik dan kecepatan informasi yang diberikan teknologi digital. Sehingga dengan memanfaatkan daya tarik teknologi digital tersebut, permainan Mul-mulan dapat menjadi konten baru permainan digital yang dapat menambah daya tarik penggunanya. Penelitian ini menggunakan metode ATUMICS untuk menganalisis elemen budaya permainan tradisional Mul-mulan. Selanjutnya elemen-elemen tersebut dipadukan dengan struktur permainan digital yang baik dan menyenangkan. Hasilnya adalah konsep perancangan permainan digital yang mengandung unsur fun dan unsur budaya yang seimbang yang disusun dalam dokumen perancangan desain game digital. Melalui penelitian ini terwujud sebuah rancangan model permainan digital baru dalam bentuk Game Design Document (GDD) yang menarik dan tetap mempertahankan nilai budaya permainan Mul-mulan di dalamnya.
\end{abstract}

Kata kunci: adaptasi, game, GDD, mul-mulan, permainan tradisional

\begin{abstract}
Like the existence of traditional games, Mul-mulan has the same problem that has been displaced by the digital games today. The effort to bring Mul-mulan into digital game becomes very possible by looking at the attractiveness and the speed of information provided by digital technology. So by using that, Mul-mulan can be a new content of digital games that can add the appeal to its users. This research uses ATUMICS method to analyze traditional culture element of Mul-mulan game. Then the elements are combined with a good and fun digital game structure. The result is the concept of designing digital games that contain elements of fun and cultural elements. Through this research obtained the model of new digital game in form Game Design Document (GDD) which interesting and maintain the cultural value of Mulmulan.
\end{abstract}

Keywords: adaptation, games, GDD, mul-mulan, traditional games 


\section{PENDAHULUAN}

Pelestarian permainan tradisional menjadi salah satu upaya untuk mempertahankan identitas budaya masyarakat di tengah perkembangan teknologi informasi yang kian pesat ini. Berbagai bentuk upaya pelestarian telah dilakukan seperti mengenalkan permainan secara langsung oleh komunitas, kompetisi dan pertunjukan permainan tradisional, dokumentasi dalam buku, foto, dan media audio visual, hingga membawa permainan tradisional ke dalam game digital. Game digital yang menjadi salah satu faktor menurunnya keberadaan permainan tradisional, kini dapat menjadi salah satu solusi pengenalan permainan tradisional ke anak. Senada dengan Purwaningsih yang mengatakan bahwa melestarikan permainan tradisional itu tidak sebatas menjaga agar tetap ada, tetapi juga dapat berkembang sesuai dengan perkembangan jaman (Khamadi \& Senoprabowo, 2016). Namun, tidak dipungkiri bahwa dalam perkembangannya itu akan ada nilai-nilai budaya yang bersinggungan dan bahkan saling meniadakan.

Beberapa contoh game digital di playstore yang mengangkat permainan tradisional saat ini adalah Peron Engklek, Balap Karungs, Egrang Jump, Macanan, dan lainnya. Hal ini menunjukkan adanya kepedulian yang cukup tinggi dari penggiat game untuk membantu mengenalkan permainan tradisional ke masyarakat. Namun, beberapa game lebih mengedepankan unsur fun dibanding nilai budaya yang bisa didapatkan oleh pemainnya atau sebaliknya terlalu banyak nilai budaya yang diberikan dengan sedikit memberikan unsur fun pada pemain, sehingga permainan terasa monoton dan cenderung tidak disukai. Idealnya game yang dibuat juga harus memperhatikan kedua faktor tersebut. Sehingga dalam proses pembuatan game harus dilakukan pendalaman nilai budaya dari permainan tradisinonal dan penerapan dari struktur game digital yang baik dan menyenangkan.

Permainan Mul-mulan adalah salah satu contoh permainan tradisional yang berbentuk permainan papan seperti dakon, macanan dan bas-basan sepur. Namun, seperti halnya keberadaan permainan tradisional lainnya, permainan ini juga sudah jarang dikenal oleh masyarakat luas (Khamadi \& Senoprabowo, 2017). Kepopuleran game digital saat ini, memberi celah bagi permainan Mul-mulan untuk dikenal kembali masyarakat dengan membawanya ke dalam bentuk permainan digital. Namun, dalam membawa permainan Mul-mulan ke dalam bentuk digital harus memperhatikan faktor nilai budaya dan fun yang seimbang bagi pemain. Sehingga perancangan konsep permainan digital Mul-mulan harus dibuat dengan matang. Game Design Document (atau biasa disebut GDD) menjadi perancangan awal sebelum membuat game (Handayani, M.Suyanto, \& Al Fatta, 2015). Game Design Document berupa kumpulan dokumendokumen yang digunakan game designer untuk menginformasikan mengenai game yang didesain (Adams, 2010). Sehingga sangat penting untuk merancang GDD dengan konsep game yang baik dan menyenangkan

Atas dasar itu, permainan Mul-mulan harus diidentifikasi dan dianalisis kandungan nilai budaya yang ada di dalamnya terlebih dahulu. Salah satunya adalah memetakan elemen tradisinya dengan metode ATUMICS. Melalui metode ATUMICS permainan 
Mul-mulan akan diurai dalam enam elemen dasarnya, yaitu teknik (Technique), kegunaan (Utility), bahan (Material), ikon (Icon), konsep (Concept), dan bentuk (Shape). Selanjutnya elemen-elemen tersebut dipadukan dengan struktur permainan digital yang baik dan menyenangkan sehingga dapat memunculkan konsep fun dan menarik dalam pembuatan game digital Mul-mulan nantinya. Selanjutnya konsep tersebut diimplementasikan dalam perancangan GDD. Akhirnya permainan digital Mulmulan mampu menunjukkan game yang menyenangkan bagi pemain tetapi juga memberikan pengalaman bermain permainan tradisional Mul-mulan.

\section{METODE PENELITIAN}

Penelitian ini menggunakan metode deskriptif kualitatif dengan memaparkan situasi dan fenomena permainan tradisional Mul-mulan pada saat ini. Pada penelitian ini variabel yang akan dikaji adalah bentuk visual arena permainan, bentuk visual alat permainan, aturan permainan, nilai budaya permainan, serta cara memainkan (gameplay) permainan tradisional Mul-mulan. Lokasi penelitian melibatkan beberapa tempat yaitu diantaranya Kampung Dolanan Nusantara di Dusun Sodongan, Desa Bumiharjo, Kecamatan Borobudur, Kabupaten Magelang; selanjutnya Museum Anak Kolong Tangga di Gedung Taman Budaya Yogyakarta lantai dua, Jalan Sriwedari no 1, Kota Yogyakarta; selanjutnya Desa Margorejo, Kabupaten Boyolali; dan Dusun Karang Pandan, Kabupaten Jepara. (Khamadi \& Senoprabowo, 2017)

Analisis data permainan Mul-Mulan menggunakan metode ATUMICS. Metode ini digunakan untuk mengkombinasikan beberapa elemen budaya tradisi dengan beberapa elemen budaya modern pada sebuah desain. Melalui metode ATUMICS produk dianalisis untuk didapatkan susunan ideal dari enam elemen dasarnya, yaitu teknik (Technique), kegunaan (Utility), bahan (Material), ikon (Icon), konsep (Concept), dan bentuk (Shape) (Nugraha, 2012). Di dalam konsep metode ATUMICS ini, perancangan sebuah produk harus menyatukan kedua level tersebut, level mikro dan level makro. Pada tahap ini akan dihasilkan model transformasi media dari media konvensional ke media digital. Selanjutnya hasil adaptasi dimasukkan ke dalam struktur permainan digital yang baik dan menyenangkan. Struktur permainan digital yang baik harus mengandung dua elemen dasar, yaitu elemen formal (Pemain, Tujuan, Prosedur, Aturan, Sumber Daya, Konflik, Batasan, dan Hasil/Akibat) dan elemen dramatis (Tantangan, Play, Alasan, Karakter, dan Cerita) (Fullerton, 2013). Selanjutnya hasil analisis dari struktur permainan digital tersebut dijadikan dasar perancangan konsep game yang dituangkan dalam sebuah Game Design Document. Game Design Document (GDD) berupa kumpulan dokumen-dokumen yang digunakan game designer untuk menginformasikan mengenai game yang didesain (Adams, 2010). Struktur dalam GDD meliputi Game overview, World game, Level design, User interface design, Content design, dan Design system.

\section{HASIL DAN PEMBAHASAN}

\subsection{Permainan Tradisional Mul-mulan}

Permainan ini biasa disebut Mul-mulan karena setiap pemain yang berhasil menyejajarkan 3 uwong dalam satu garis mengatakan "mul". Dari kata tersebut, 
akhirnya muncul kata ulang "mul" berakhiran /an/ untuk menyebut permainan ini. Anak-anak yang mendominasi permainan ini adalah anak laki-laki. Namun anak perempuan kadang juga memainkannya. Permainan yang bersifat pertandingan ini, setidaknya dimainkan oleh 2 anak yang saling berhadapan. Bisa dimainkan kelompok, tetapi harus selalu genap. Permainan ini lebih bersifat rekreatif kompetitif dengan mengutamakan berpikir. Mereka yang bermain permainan ini biasanya seusia SD. Namun tidak jarang pula remaja atau orang dewasa ikut-ikutan bermain permainan ini. Permainan yang memerlukan kecermatan ini biasa dimainkan di tempat terang. (Dharmamulja, 2005)

Apabila ada dua anak, misalkan pemain A dan B, atau lebih (dalam kelompok) yang ingin bermain Mul-mulan, maka mereka segera bersepakat untuk menentukan tempat bermain. Tidak lupa masing-masing pemain juga sudah harus mempersiapkan uwong berupa kerikil dan sejenisnya. Setiap orang dalam memilih uwong bebas, asalkan satu pemain dengan pemain lain tidak boleh sama. Artinya jika pemain A telah memilih uwong berupa kecik tanjung, maka pemain B harus menggunakan kerikil. Pembedaan uwong ini hanya untuk memudahkan permainan agar tidak keliru. Setiap pemain harus mencari uwong sebanyak 9 buah.

Setelah menyepakati tempat yang teduh dan nyaman, serta masing-masing membawa orang-orangan, tidak lupa salah satunya juga menyiapkan kapur atau alat tulis lainnya (sesuai dengan media yang dipakai). Jika bermain di atas lantai atau ubin, bisa menggambar dengan dengan menggunakan kapur, spidol, pecahan tembikar dan sebagainya. Sementara uwong bisa diwakili dengan kehadiran. kerikil, gelindingan kertas, potongan ranting, atau pun biji-bijian (sawo, tanjung, sirsat, dan sebagainya). Kedua pemain lalu duduk saling berhadapan. Salah satu pemain segera menggambar bangun bujur sangkar sama sisi lapis tiga di atas ubin atau lantai seperti berikut.

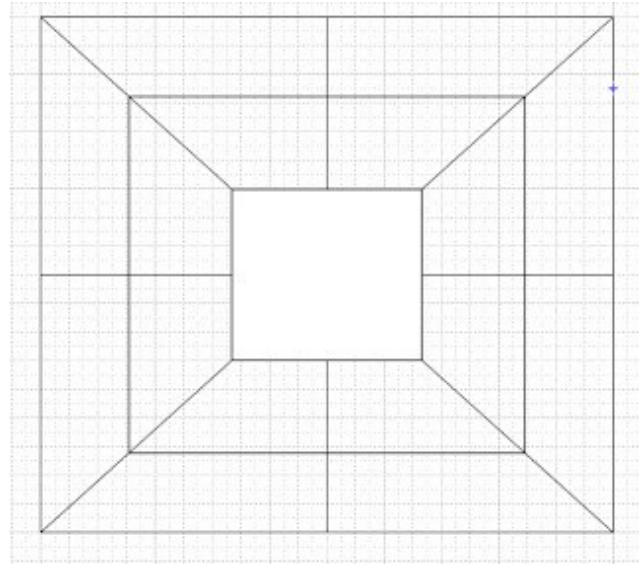

Gambar 1. Arena permainan Mul-mulan [Sumber: Dharmamulja, 2005]

Langkah pertama, keduanya harus melakukan sut. Jika pemain A menang, ia main duluan. Kemudian pemain A meletakkan satu uwong di titik yang ada di antara persilangan garis secara bebas. Lalu pemain B juga meletakkan satu uwong secara 
bebas di titik lainnya yang masih kosong. Kedua pemain berusaha untuk mencegah atau menutup pihak lawan yang orang-orangannya hampir sejajar dalam jumlah tiga buah. Maka permainan di sini membutuhkan kecermatan dan ketelitian berpikir dari setiap pemain. Lalu dilanjutkan oleh pemain A lagi. Jika sampai waktunya salah satu pemain telah meletakkan lebih dari 3 orang-orangannya di atas titik yang ada, dan kebetulan pemain A permainannya sangat jitu dan tidak terpantau oleh pemain $B$, maka pemain A berhasil meletakkan 3 orang-orangannya dalam satu baris yang sejajar. Maka terpaksa pemain A mengambil salah satu uwong milik pemain B yang ada di petak permainan secara bebas. Di sini, pemain B sudah kehilangan 1 orang-orangan.

Permainan bisa dilanjutkan terus hingga ada salah satu pemain yang menyejajarkan 3 orang-orangannya lagi. Demikian seterusnya permainan akan berlangsung hingga salah satu pemain kehabisan orang-orangannya atau setidaknya berkurang orangorangannya. Apabila ada salah satu pemain yang sudah berkurang atau kehabisan orang-orangannya dan kebetulan ia sudah menyerah, maka ia dianggap sebagai pemain kalah. Sesuai dengan konsekuensinya atau kesepakatan awal, jika pemain kalah harus menerima hukuman, maka ia harus menerima hukuman. Misalkan hukuman bisa berupa menggendong, menampar tangan, atau menyanyi.

\subsection{Adaptasi Elemen Budaya Permainan Mul-Mulan ke dalam Struktur Permainan Digital.}

Permainan Mul-mulan dipetakan elemen budayanya sebelum dipadukan dengan struktur permainan digital. Berikut adalah analisis permainan Mul-mulan dalam metode ATUMICS. Permainan Mul-mulan dianalisis menurut enam elemen dasarnya, yaitu teknik (Technique), kegunaan (Utility), bahan (Material), ikon (Icon), konsep (Concept), dan bentuk (Shape) sebagai berikut:

1. Technique

Secara teknik, permainan Mul-mulan dapat dijabarkan sebagai berikut:

a) Teknik bermain; memuat jumlah pemain yang terlibat yaitu minimal dua pemain, dan memuat prosedur dan aturan permainan Mul-mulan hingga hasil kalah dan menang dalam permainan.

b) Keahlian (skill) pemain dalam memainkan permainan Mul-mulan. Pemain harus memiliki kemampuan berstrategi dan konsentrasi yang lebih baik untuk dapat memainkan dan memenangkan permainan. Faktor usia sering menentukan di bidang ini.

c) Teknologi; memuat penggunaan semua potensi sarana dan proses dalam permainan yang masih secara manual, yaitu kendali permainan langsung dari pemain, tidak otomatis seperti komputer.

d) Peralatan (tool) yang digunakan pun sangat sederhana yaitu arena permainan yang digambar dan sejumlah uwong atau pion permainan dari benda-benda kecil di sekitar.

2. Utility

Utility memiliki beberapa maksud di antaranya sebagai berikut;

a) Fungsi; Mul-mulan biasa dimainkan untuk mengisi waktu luang dan dapat dilakukan sembarang waktu. 
b) Kegunaan; Mul-mulan dapat melatih kecerdasan daya pikir dan konsentrasi pemainnya.

c) Kebutuhan; meskipun termasuk permainan yang berat karena lebih membutuhkan olah pikir dibanding olahraga yang aktif, tetapi Mul-mulan seperti permainan tradisional lainnya juga dapat memenuhi kebutuhan hiburan anakanak khususnya yang menyukai jenis permainan ini.

\section{Material}

Bahan-bahan yang digunakan dalam permainan Mul-mulan menggunakan bahan mudah dicari dan sederhana, seperti kerikil atau biji-bijian buah (seperti: sawo, asam, tanjung, dan lainnya). Sementara arena permainan berupa persegi empat bisa digambar dengan kapur, pensil, atau benda lain, menyesuaikan lahannya.

4. Icon

Sesuai dengan nama permainannya, Mul-mulan dapat diidentifikasi dengan jenis pion yang dimainkan yaitu adanya wong. Selain itu permainan Mul-mulan memiliki bentuk arena permainan yang khas, yang tidak sama dengan permainan lain. Sehingga ikon permainan Mul-mulan juga dapat dilihat dari bentuk arena permainannya berupa persegi empat berlapis tiga.

5. Concept

Konsep atau faktor tersembunyi terlihat dalam sebuah objek melalui tampilan visualnya, atau pada bentuk (shape), ikon (icon), atau kegunaan (utility) sebuah objek/artefak. Unsur konsep dalam permainan Mul-mulan ini adalah bentuk arena permainan dan gameplaynya. Bentuk arena berupa persegi empat yang berlapis tiga yang senada dengan gameplay permainan untuk mengurutkan tiga pion secara berdampingan dalam garis lurus horisontal, vertikal, maupun diagonal. Saat pion berhasil berjajar tiga tersebut, pemain akan berteriak Mul yang dalam bahasa Jawa Mul berarti kemulyaan, kemenangan. Angka tiga dalam Jawa dapat bermakna Tri (tiga kehidupan/tingkatan; Alam Ruh/Kandungan, Duniawi, Akherat), Krida (olah, perbuatan, tindakan). Konsep gameplay Mul-mulan tidak hanya mementingkan strategi menyerang tetapi bagaimana menimalisir kesalahan. Sekali salah langkah akan lebih mudah kehilangan pion.

6. Shape

Unsur shape yang dapat diukur dalam Mul-mulan adalah bentuk arena permainannya. Hal ini dikarenakan bentuk pion yang digunakan dapat berupa apa saja asalkan berukuran sedang atau kecil yang disesuaikan dengan besar arena permainan yang dibuat. Masing-masing pion pemain memiliki bentuk yang tidak sama agar dapat dikenali kepemilikannya. Misalnya; pemain 1 memakai pion dari batu kerikil maka pemain 2 tidak menggunakan batu kerikil, mungkin biji sawo kecik.

Elemen-elemen Mul-mulan level mikro metode ATUMICS selanjutnya diadaptasikan ke dalam struktur permainan digital yang memuat elemen formal dan elemen dramatis sebuah perancangan game. Hal ini dilakukan untuk menemukan perpaduan yang sesuai sebagai dasar perancangan model permainan digital selanjutnya. 
Tabel 1. Adaptasi permainan Mul-mulan ke dalam struktur permainan digital

[Sumber: Khamadi \& Abi Senoprabowo, 2017]

\begin{tabular}{|c|c|c|c|c|c|c|}
\hline \multirow{2}{*}{$\begin{array}{c}\text { Elemen } \\
\text { Permainan } \\
\text { Digital }\end{array}$} & \multicolumn{6}{|c|}{ Artefak ( Mul-mulan ) } \\
\hline & Technique & Utility & Material & Icon & Concept & Shape \\
\hline Pemain & $\begin{array}{l}\text { Dimainkan } \\
\text { oleh } 2 \\
\text { Pemain: } \\
\text { Pemain A vs } \\
\text { Pemain B } \\
\end{array}$ & - & $\begin{array}{l}\text { Material } \\
\text { Peralatan } \\
\text { diganti } \\
\text { Material } \\
\text { Visual }\end{array}$ & - & - & - \\
\hline Tujuan & - & $\begin{array}{l}\text { Tujuan: } \\
\text { Mengalah- } \\
\text { kan pemain } \\
\text { lain }\end{array}$ & - & - & - & - \\
\hline Prosedur & $\begin{array}{l}\text { Rincian } \\
\text { instruksi } \\
\text { permainan } \\
\text { terkait } \\
\text { langkah pion } \\
\text { wong dan } \\
\text { bentuk arena } \\
\text { permainan }\end{array}$ & - & - & $\begin{array}{l}\text { Bentuk } \\
\text { Arena } \\
\text { Permainan }\end{array}$ & $\begin{array}{l}\text { Nilai budaya } \\
\text { Jawa terkait } \\
\text { bentuk arena } \\
\text { dan konsep } \\
\text { gameplay } \\
\text { permainan }\end{array}$ & $\begin{array}{l}\text { Bentuk, } \\
\text { ukuran, } \\
\text { proporsi pion } \\
\text { dan arena } \\
\text { permainan }\end{array}$ \\
\hline Aturan & $\begin{array}{l}\text { Aturan } \\
\text { permainan } \\
\text { Mul-mulan } \\
\text { dibuat dengan } \\
\text { konsep level }\end{array}$ & $\begin{array}{l}\text { Mengalah- } \\
\text { kan setiap } \\
\text { tantangan } \\
\text { dalam } \\
\text { konsep level }\end{array}$ & - & $\begin{array}{l}\text { Bentuk } \\
\text { arena } \\
\text { permainan }\end{array}$ & $\begin{array}{l}\text { Konsep level } \\
\text { didasarkan } \\
\text { pada nilai } \\
\text { budaya angka } \\
3 \text { di Jawa }\end{array}$ & $\begin{array}{l}\text { Pion } \\
\text { divisualkan } \\
\text { sesuai } \\
\text { konsep level }\end{array}$ \\
\hline $\begin{array}{l}\text { Sumber } \\
\text { Daya }\end{array}$ & - & - & $\begin{array}{l}\text { Pemberian } \\
\text { item sumber } \\
\text { daya }\end{array}$ & - & - & - \\
\hline Konflik & $\begin{array}{l}\text { Langkah } \\
\text { pemain terkait } \\
\text { manajemen } \\
\text { pion dan } \\
\text { bentuk arena } \\
\text { permainan } \\
\text { untuk } \\
\text { menyerang } \\
\text { pion lawan }\end{array}$ & - & - & - & $\begin{array}{l}\text { Nilai budaya } \\
\text { Jawa terkait } \\
\text { bentuk arena } \\
\text { dan konsep } \\
\text { gameplay } \\
\text { permainan }\end{array}$ & - \\
\hline Batasan & $\begin{array}{l}\text { Batasan dalam } \\
\text { aturan } \\
\text { permainan } \\
\text { terkait bentuk } \\
\text { arena dan } \\
\text { jumlah pion }\end{array}$ & - & - & - & $\begin{array}{l}\text { Nilai budaya } \\
\text { Jawa terkait } \\
\text { bentuk arena } \\
\text { dan konsep } \\
\text { gameplay } \\
\text { permainan }\end{array}$ & - \\
\hline $\begin{array}{l}\text { Hasil/ } \\
\text { Akibat }\end{array}$ & $\begin{array}{l}\text { Menang dan } \\
\text { kalah dalam } \\
\text { permainan }\end{array}$ & $\begin{array}{l}\text { Mengalah } \\
\text { kan setiap } \\
\text { tantangan } \\
\text { dan pemain } \\
\text { lain untuk } \\
\text { menang }\end{array}$ & - & - & - & - \\
\hline
\end{tabular}




\begin{tabular}{|c|c|c|c|c|c|c|}
\hline \multirow{2}{*}{$\begin{array}{l}\text { Elemen } \\
\text { Permainan } \\
\text { Digital }\end{array}$} & \multicolumn{6}{|c|}{ Artefak ( Mul-mulan ) } \\
\hline & Technique & Utility & Material & Icon & Concept & Shape \\
\hline Tantangan & $\begin{array}{l}\text { Keahlian } \\
\text { pemain lawan }\end{array}$ & $\begin{array}{l}\text { Perasaan } \\
\text { senang dan } \\
\text { puas } \\
\text { bermain }\end{array}$ & - & - & & - \\
\hline Play & - & $\begin{array}{l}\text { Memecah- } \\
\text { kan masalah } \\
\text { dengan } \\
\text { menyenang- } \\
\text { kan }\end{array}$ & - & - & - & - \\
\hline Alasan & - & $\begin{array}{l}\text { Memenuhi } \\
\text { kebutuhan } \\
\text { hiburan bagi } \\
\text { anak }\end{array}$ & - & - & - & - \\
\hline Karakter & $\begin{array}{l}\text { Pion } \\
\text { Permainan } \\
\text { tampil secara } \\
\text { visual }\end{array}$ & - & $\begin{array}{l}\text { Material Pion: } \\
\text { Material } \\
\text { Visual } \\
\text { (Digital) }\end{array}$ & - & - & $\begin{array}{l}\text { Bentuk, } \\
\text { ukuran, } \\
\text { proporsi pion } \\
\text { permainan } \\
\text { diwujudkan } \\
\text { secara visual }\end{array}$ \\
\hline Cerita & - & $\begin{array}{l}\text { Menyelesai- } \\
\text { kan cerita } \\
\text { yang } \\
\text { diberikan } \\
\text { (penambah- } \\
\text { an) }\end{array}$ & - & - & - & - \\
\hline
\end{tabular}

Dari perpaduan kedua jenis elemen budaya tersebut terlihat bahwa elemen yang dapat dipertahankan dalam permainan Mul-mulan adalah elemen Concept, Icon, dan Shape. Sedangkan pada elemen Material terjadi perubahan material tradisional menjadi material visual (digital). Hal ini terjadi karena pada permainan digital peralatan yang digunakan sudah menggunakan bahan yang berbau teknologi digital seperti layar komputer sebagai tempat arena permainan dan pion pun disediakan di dalam tampilan visual pada layar tersebut. Kerikil dan biji sawo kecik masih bisa dipertahankan secara visual pada layar permainan komputer.

Selain itu dari tabel di atas juga diketahui terdapat elemen Mul-mulan yang tidak memenuhi elemen pada struktur permainan digital yaitu elemen sumber daya dan cerita. Hal ini terjadi karena pada elemen sumber daya; dalam permainan Mul-mulan tidak ada variabel peralatan permainan yang dibutuhkan bernilai tinggi dan langka. Pion sebagai peralatan main tidak memenuhi syarat langka karena jumlahnya memang dibatasi untuk setiap variasi permainannya. Jumlah pion untuk masing-masing pemain tidak akan bisa bertambah dalam permainan. Karena langka sebagai sebuah sumber daya dalam permainan berarti ada potensi keberadaannya tetapi jumlahnya sedikit dan membutuhkan usaha tertentu untuk mendapatkannya. Selain itu sumber daya akan mempermudah mencapai tujuan game jika digunakan. Elemen cerita tidak 
dimiliki oleh permainan Mul-mulan karena pada dasarnya permainan ini permainan papan abstrak.

Secara umum dengan mengacu pada Fundamentals of Game Design (Adams, 2010) dan Game Design (Pulsipher, 2012) konsep perancangan permainan digital Mul-mulan yang didasarkan pada aturan permainan dasar permainan tradisional Mul-mulan menekankan pada beberapa aspek, yaitu:

a. Turn-based strategy game yaitu permainan strategi dengan pemain memainkan gilirannya secara bergantian. Strategi berarti perencanaan, termasuk mengambil keuntungan situasi dan sumber daya, mengantisipasi gerakan lawan, mengetahui dan meminimalisir kekurangan.

b. Konsep leveling yang mengacu pada struktur game digital yang baik dengan menambahkan unsur cerita sebagai penguat.

c. Pemberian cerita yang lebih baik kepada pemain dengan membuat narasi cerita besar yang diwujudkan dalam penggalan cerita setiap levelnya. Pesan cerita akan diarahkan kepada konsep mul yaitu kemuliaan atau kemenangan serta konsep angka 3 dalam budaya Jawa, hal ini disesuaikan dengan konsep tiga dalam bentuk arena permainan dan jumlah pion yang harus disejajarkan berdampingan untuk menang.

d. Interaksi pemain terhadap narasi cerita yang disampaikan. Pemain akan diberikan misi yang berbeda pada setiap level sesuai konsep leveling dan cerita yang telah dijelaskan sebelumnya.

e. Pion divisualisasikan berupa karakter yang memiliki karakteristik berbeda yang menarik.

f. Bentuk arena papan permainan digital divisualisasikan dengan latar background sesuai dengan lingkungan yang dibangun dalam cerita.

g. Pemberian hadiah dan hukuman (reward and punishment) pada permainan Mulmulan tradisional berupa menggendong pemenang dan aktifitas hukuman lain diganti dengan pemberian hadiah dan hukuman berupa bertambah atau berkurangnya item yang dibutuhkan dalam permainan. Hal ini dilakukan untuk memberikan motivasi lebih agar pemain merasa diapresiasi dan berusaha memainkan terus untuk mendapatkan reward yang lebih atau mengulangi permainan akibat mendapat punishment.

h. Terdapat item sumber daya yang dapat ditemukan seiring peningkatan level seperti sejumlah emas dan karakter baru yang menjadi reward dan dapat digunakan pada level selanjutnya.

\subsection{Penyusunan model rancangan permainan digital Mul-mulan dalam perancangan Game Design Document (GDD)}

Struktur dalam GDD Mul-mulan ini didapatkan dari hasil konsep adaptasi elemen permainan tradisional Mul-mulan ke dalam struktur permainan digital yaitu meliputi meliputi: 


\section{a. Game overview}

Berisi informasi tentang beberapa aspek game yaitu

1) Game Concept

Game Mul-mulan berupa board game dengan gameplay turn based strategy yang menyenangkan dikemas dalam sebuah cerita petualangan dalam setting masa kerajaan Nusantara dengan visual yang atraktif. Game Mul-mulan tidak hanya mementingkan strategi menyerang tetapi bagaimana menimalisir kesalahan. Sekali salah langkah akan lebih mudah kehilangan pion. Jumlah dan jenis koin menjadi kunci utama kemenangan.

2) Design Goal

Tujuan dari perancangan game ini adalah

a) Mengedukasi pemain untuk lebih mengenal permainan papan tradisional Mulmulan.

b) Memberikan pengalaman baru bagi pemain terhadap gameplay game unik adaptasi permainan papan tradisional Mul-mulan.

c) Menyediakan board game digital yang mengangkat budaya permainan tradisional.

d) Mengembangkan gameplay yang menyenangkan, berdasarkan:

1. Discovery, pemain menemukan potongan cerita game, level baru, dan mendapatkan achievement dan prize/reward dalam game.

2. Advancement, pion menjadi lebih kuat dan spesial seiring peningkatan level.

3. Power, board game ini bercerita tentang meningkatkan diri untuk melawan musuh dan memenangkannya dalam berbagai level game.

e) Menyediakan aset game yang mengedepankan pada kebudayaan lokal seperti atribut aset dan environment game sesuai dengan konteks cerita yang disampaikan.

3) Game Genre

Game Mul-mulan ini bergenre Digital Board Game dengan konsep Turn Based Strategy yaitu pemain menyerang secara bergiliran.

4) Target Audience

Sasaran ideal dari game ini dapat dijabarkan sebagai berikut;

a) Laki-laki usia 12 tahun ke atas.

b) Memiliki smartphone dan memainkan mobile games.

c) Menyukai game khususnya genre board game.

Meskipun lebih menyasar ke pemain remaja, tetapi secara keseluruhan game ini menyediakan gameplay menyenangkan yang dapat dinikmati oleh pemain secara umum.

5) Game Flow

Pemain dapat memilih mode permainan yang akan dimainkan yaitu Campaign dan Challenge.

a) Mode permainan Campaign

Yaitu mode permainan sesuai cerita yang diberikan dalam game. Pemain harus memulai dari training level hingga sampai level akhir yaitu level 3. 
b) Mode permainan Challenge.

Yaitu mode permainan dimana pemain langsung melakukan duel terhadap karakter lawan. Mode ini tidak terikat pada cerita yang diberikan dalam game.

\section{b. World game}

Yaitu merancang dunia dalam game, setting kejadian, dan tema keseluruhan dari game dibahas di dalamnya. World game meliputi;

1) Back Story

Berlatar masa kerajaan abad ke-14 di tanah Jawa, seorang pendekar Arya Dhanu berjuang untuk mendapatkan koin Raja dalam tanding mul-mulan demi mengembalikan lagi kemuliaan kerajaan. Saat itu kerajaan dipimpin oleh Raja lalim yang menindas rakyat. Raja memiliki bawahan yang menguasai berbagai koin keramat yang harus ditaklukan terlebih dahulu. Berbekal koin biasa, Arya harus memenangkan setiap tanding mul-mulan untuk mendapatkan koin Raja.

2) Story Plot

Alur cerita disampaikan dalam tahapan level sebagai berikut;

a) Training level

Arya Dhanu belajar menggunakan koin di dalam tanding mul-mulan.

b) Level 1

Arya Dhanu mulai mengembara untuk mendapatkan koin keramat agar bisa melawan koin Raja. Arya Dhanu melawan pendekar lain yang sama-sama mengumpulkan koin keramat.

c) Level 2

Arya Dhanu telah berhasil mengumpulkan beberapa koin keramat, tetapi kekuatan yang dimiliki koin keramat tidak cukup kuat. Akhirnya sesampainya di ibukota kerajaan, Arya mulai mengumpulkan koin keramat yang lebih sakti dengan melawan prajurit kerajaan.

d) Level 3

Kemenangan Arya Dhanu membuat gempar kerajaan. Arya Dhanu harus berhasil melawan pasukan terkuat tersebut untuk dapat melawan Raja yang memiliki koin Raja.

3) General Look and Feel of World

Gaya visual yang diangkat dalam game ini lebih mengedepankan pada visual 2 Dimensi (2D) yang simple yaitu gaya kartun. Gaya visual game ini dipengaruhi oleh beberapa game yang ada saat ini seperti Brave frontier, plant vs zombie, dan sebagainya.

4) Areas

Cerita berlatar di masa kerajaan Jawa abad ke-14. Setting game meliputi wilayah pedesaan, ibu kota kerajaan, hingga wilayah kerajaan yang masih kental dengan budaya kerajaan seperti bangunan candi.

5) Visual Theme

Visual masa kerajaan dimana kemiskinan, dan kejahatan meraja lela. Rakyat tidak makmur dan penindasan di mana-mana. 
c. Level design,

Yaitu mendesain setiap levelnya, termasuk fitur, tingkat kesulitan, dan tema dari setiap level.

1) Level Diagram

Tabel 2. Susunan tingkatan level

[Sumber: Khamadi \& Abi Senoprabowo, 2017]

\begin{tabular}{|c|c|c|}
\hline \multicolumn{3}{|c|}{ Training Level - Pedesaan } \\
\hline \multicolumn{3}{|c|}{ Level 1 - Pedesaan } \\
\hline Stage A - pagi hari & Stage B - sore hari & Stage $\mathrm{C}-$ malam hari \\
\hline $\begin{array}{l}\text { Musuh level 1, } \\
\text { koin biasa, } \\
\text { Jumlah koin } 9\end{array}$ & $\begin{array}{l}\text { Musuh level } 1 \text {, } \\
\text { koin keramat } 1 \text {, } \\
\text { Jumlah koin } 9\end{array}$ & $\begin{array}{l}\text { Mid-boss, } \\
\text { koin keramat 2, } \\
\text { Jumlah koin } 9\end{array}$ \\
\hline \multicolumn{3}{|c|}{ Level 2 - Ibu kota Kerajaan } \\
\hline Stage A - pagi hari & Stage B - sore hari & Stage $\mathrm{C}$ - malam hari \\
\hline $\begin{array}{l}\text { Musuh level 2, } \\
\text { Koin keramat } 3 \text {, } \\
\text { Jumlah koin } 12\end{array}$ & $\begin{array}{l}\text { Musuh level 2, } \\
\text { koin keramat } 3 \text {, } \\
\text { Jumlah koin } 12\end{array}$ & $\begin{array}{l}\text { Mid-boss level 2, } \\
\text { koin keramat 4, } \\
\text { Jumlah koin } 12\end{array}$ \\
\hline \multicolumn{3}{|l|}{ Level 3-Kerajaan } \\
\hline Stage A - pagi hari & Stage B - sore hari & Stage C-malam hari \\
\hline $\begin{array}{l}\text { Musuh level 3, } \\
\text { Koin keramat 4, } \\
\text { Jumlah koin } 15\end{array}$ & $\begin{array}{l}\text { Musuh level } 3 \text {, } \\
\text { koin keramat } 5 \text {, } \\
\text { Jumlah koin } 15\end{array}$ & $\begin{array}{l}\text { Bos Raja, } \\
\text { koin keramat } 5 \text {, koin Raja } \\
\text { Jumlah koin } 18\end{array}$ \\
\hline
\end{tabular}

2) Challenge

a) Training level

Level pengenalan gameplay permainan mul-mulan. Pemain cukup mengikuti tutorial yang diberikan.

b) Level 1

Terdiri 3 stage melawan musuh level 1. Pemain dibekali jenis dan jumlah koin yang terbatas. Peningkatan kesulitan di setiap stage yang berupa jenis koin yang dimiliki musuh.

c) Level 2

Terdiri dari 3 stage melawan musuh level 2 yang memiliki jumlah koin keramat lebih banyak dan kemampuan yang lebih baik dari musuh level 1. Jumlah koin yang dimainkan bertambah. Kesulitan stage meningkat hingga melawan mid boss.

d) Level 3

Terdiri dari 3 stage. Peningkatan tantangan dan kesulitan berupa karakter musuh level 3 dengan jumlah dan jenis koin yang lebih banyak dan lebih kuat. Terjadi peningkatan setiap stage hingga stage akhir melawan bos Raja yang memiliki koin raja dengan kemampuan lebih kuat. 


\section{d. User interface design,}

Yaitu merancang Screen Flow, Screen Description dan mendesain interaksi user.

1) Screen Flow

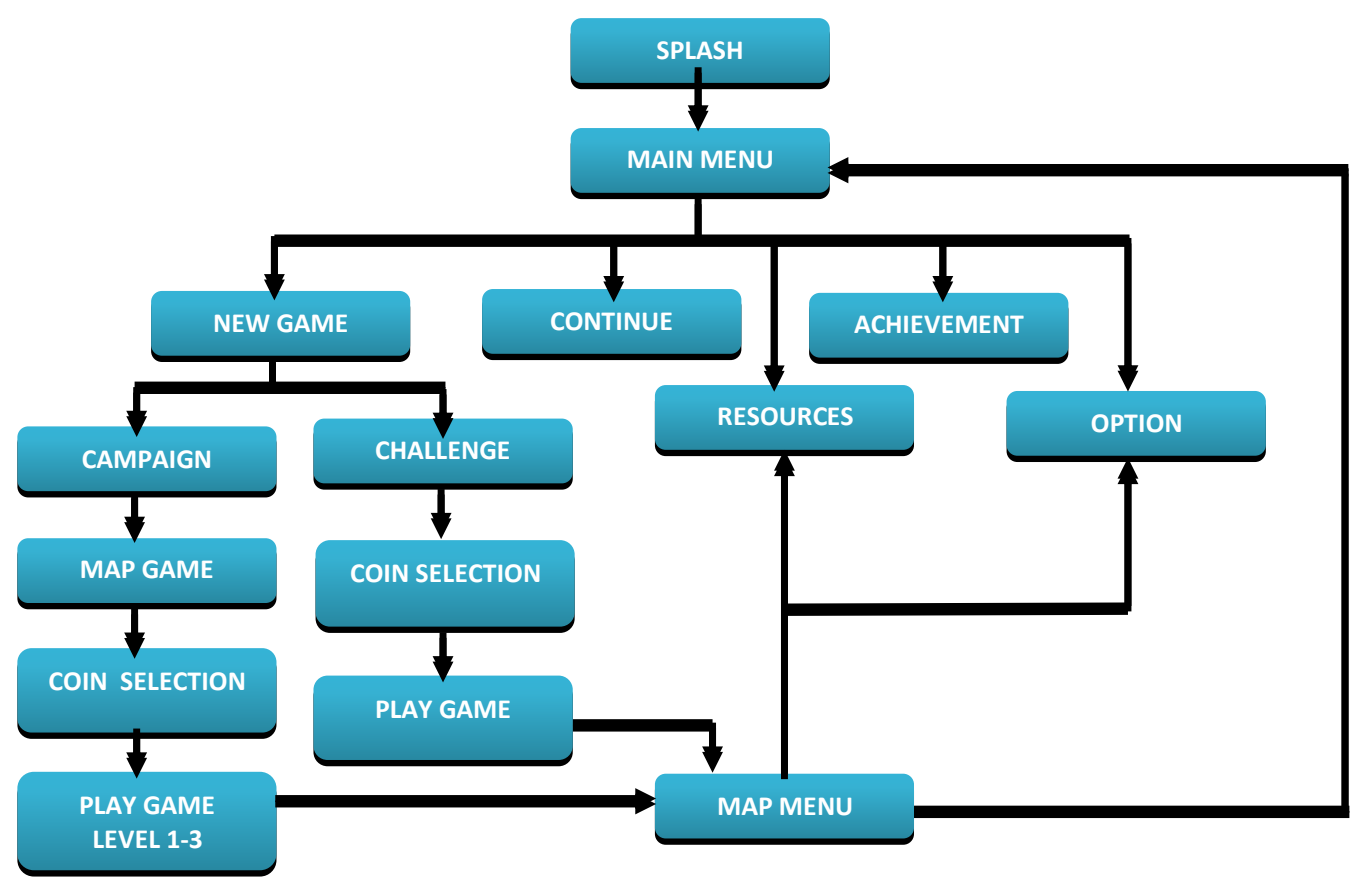

Gambar 2. Alur permainan

[Sumber: Khamadi \& Abi Senoprabowo, 2017]

a. Splash

Layar awal untuk memperkenalkan logo game MUL-MULAN

b. Main Menu

Menyajikan keseluruhan pilihan bagi pemain dan menggambarkan ilustrasi yang memperkenalkan look and feel dari game MUL-MULAN.

c. New Game: Campaign/Challenge

Menunjukkan pilihan bagi pemain untuk memulai game yang baru. Terdapat dua mode permainan yaitu Campaign (bermain sesuai cerita) dan Challenge (bermain tidak terikat cerita)

d. Continue

Memperlihatkan game yang telah dimainkan pemain sebelumnya dan berisi pilihan untuk meneruskan game yang terakhir dimainkan

e. Resources

Berisi informasi detail yang dapat diakses oleh pemain terkait karakter dan ensiklopedi. Informasi dapat terbuka saat pemain berhasil menyelesaikan sebuah misi/level.

f. Achievement

Berisi galeri reward yang berhasil didapatkan pemain setelah menyelesaikan misi game. Berisi tumbnail gambar dari reward yang dapat dilihat secara jelas dengan mengtouchnya. 
g. Option

Berisi pilihan bagi pemain untuk mengatur atribut game, seperti volume suara dan volume musik.

h. Map Game

Berisi pilihan terkait storyline berupa map level yang harus diselesaikan oleh pemain.

i. Coin Selection

Pemain dapat memilih koin yang akan digunakan sebelum memulai permainan. Berisi dialog koin yang disertai informasi status koin.

j. Play Game

Dimana permainan berlangsung. Berisi HUD yang berisi potrait karakter dan coin bar. Interaksi pemain dalam menggerakkan koin dengan mentouchnya dan mengarahkan arah gerakan sesuai blok arena permainan.

k. Map Menu

Dapat diakses selama permainan yang berupa menu pause. Pemain dapat mengakses informasi di resources dan option, bahkan dapat keluar dari permainan untuk kembali ke main menu game.

\section{2) Movement}

Pergerakan di dalam game baik pergerakan GUI dan koin karakter dapat dilakukan oleh pemain dengan touchscreen pada perangkat mobile.

3) Actions

Interaksi yang dapat dilakukan oleh pemain dalam game ini adalah:

a) Switches and Buttons

Pemain dapat memilih jenis menu yang diinginkan melalui tombol/button yang tersedia pada GUI, maupun memilih jenis koin yang akan dimainkan dalam sebuah stage. Selain itu pada saat permainan berlangsung pemain dapat memilih koin yang akan digerakkan.

b) Pick Up, Carry, and Drop

Pada beberapa GUI misal saat memilih koin yang akan dimainkan dalam Stage, pemain dapat mengambil dan menempatkannya pada kotak dialog yang telah disediakan. Sehingga koin yang akan dimainkan oleh pemain bisa dicustom oleh pemain sendiri. Selama permainan, koin diambil dari coin bar untuk diletakkan pada bidang di arena.

c) Reading

Interaksi yang harus dilakukan oleh pemain untuk mendapatkan keseluruhan informasi dalam game adalah dengan membaca informasi yang tampil dalam GUI game seperti menu, opening scene, scene dialog, cut scene, hingga tampilan informasi dalam game.

4) Replaying and Saving

Pemain dapat me-replay stage/level yang telah dilewati sebelumnya. Bagi stage/level yang belum terbuka (locked), pemain harus terlebih dahulu menyelesaikan stage/level tersebut. Setiap pemain berhasil melewati sebuah stage/level maka perolehan poin dan reward secara otomatis tersimpan dalam database. Namun, saat pemain memilih untuk memainkan game baru, maka seluruh perolehan poin, reward akan kembali ke posisi default awal. 


\section{5) Cheats and Easter Eggs}

Cheat hanya digunakan saat testing untuk mempermudah quality Assurance. Cheat dibuat sedemikian rupa agar tidak dapat dibajak. Cheat akan dihapus saat game telah dilaunching.

e. Content design,

Yaitu merancang karakter, file audio, video dan lain sebagainya.

1) Characters

Karakter dapat dibagi menjadi dua jenis karakter yaitu karakter manusia sebagai avatar pemain dan lawan, dan karakter koin yang menjadi alat permainan di arena.

Karakter Manusia;

a) Karakter Protagonis

Karakter utama, Arya Dhanu, seorang pemuda tampan berpakaian layaknya pendekar Jawa jaman kerajaan. Memiliki jimat yang berupa tas penyimpanan koinnya.

b) Karakter Antagonis

1. Pendekar biasa; Musuh level 1, berparas sangar dan memiliki kemampuan yang setara dengan karakter utama. Beberapa memiliki koin keramat dengan jumlah yang terbatas.

2. Bos pendekar; mid-boss level 1, berparas sangar yang memiliki kemampuan di atas pendekar biasa yaitu memiliki jumlah koin keramat yang lebih banyak. Koin keramat tipe penyerang biasa.

3. Prajurit kerajaan; Musuh level 2, berperawakan tegap dan gagah serta memiliki kemampuan yang tinggi dengan memiliki jumlah koin dan jenis koin yang lebih banyak. Koin keramat tipe bertahan biasa.

4. Bos prajurit; mid-boss level 2, berperawakan tinggi tegap, gagah, dan garang. Memiliki kemampuan yang tinggi dalam menyerang dan bertahan dengan jumlah koin dan jenis yang lebih banyak dari prajurit kerajaan. Koin keramat tipe bertahan dan penyerang sedang.

5. Pasukan Raja; Musuh level 3, berparas tampan dan berkekuatan tinggi dengan jumlah dan jenis koin semakin baik. Koin keramat tipe bertahan dan penyerang tinggi.

6. Bos Raja; berparas garang, licik, dan kejam. Memiliki koin Raja yang kekuatannya di atas koin keramat. Jumlah koin sangat banyak dengan variasi jenis koin keramat yang banyak pula.

Karakter Koin;

a) Koin biasa; tidak memiliki kekuatan spesial

b) Koin keramat; memiliki dua tipe yaitu tipe bertahan (kekuatan freeze, heal, dan sebagainya) dan tipe penyerang (kekuatan switch, move, dan sebagainya)

c) Koin Raja; penguasa kekuatan koin keramat, memunculkan kekuatan yang dapat dipilih sesuka hati. 


\section{2) Sound dan Music}

Interaksi GUI diberikan sound $f x$ berupa sound tombol untuk tombol Menu, tombol Reward dan tombol Play Game. Sound $f x$ diberikan pada aksi koin di dalam Play Game yaitu saat koin diletakkan, koin mengeluarkan kekuatan, koin disingkirkan, dan sebagainya. Musik background diberikan sesuai dengan setting arena seperti di pedesaan yang asri penuh suara alam, di ibukota kerajaan yang hiruk pikuk dengan banyaknya kegiatan, dan di kerajaan yang tenang tapi mencekam.

3) Video

Berupa opening animation, opening scene play game dan cut scene karakter selama play game serta ending game.

\section{f. Design system}

Yaitu merancang peraturan dalam permainan yang meliputi;

\section{1) Gameplay}

Pemain memainkan koin di atas arena papan mul-mulan dengan eksplorasi sebatas tampilan setting arena dalam visual 2D. Masing-masing pemain memainkan koin di atas arena sesuai aturan permainan. Pemain secara bergiliran dapat menempatkan koinnya pada bidang arena yang dikehendaki. Jika semua koin telah ditempatkan, koin dapat dipindahkan ke satu bidang terdekat baik ke kanan, kiri, atas, bawah, diagonal. Jenis koin keramat memiliki kekuatan spesial yang dapat menguntungkan pemain. Koin keramat bisa didapatkan dengan mengalahkan musuh yang kuat. Game ini menyediakan 3 level utama dimana pemain harus melawan mid-stage bos, hingga akhirnya melawan bos utama di level terakhir.

2) Game Progression

Gameplay dalam game Mul-mulan ini mengharuskan pemain untuk mengalahkan setiap musuh dalam stage agar dapat maju ke level selanjutnya.

3) Mission/Challenge Structure

Misi utama dalam permainan ini adalah mengalahkan bos utama di level akhir. Selain itu terdapat misi tambahan di setiap levelnya seperti misi mendapatkan koin keramat. Sedangkan struktur tantangan dalam game ini dibangun oleh beberapa variabel dalam game yaitu.

a) Batasan jumlah koin yang dapat digunakan.

b) Jenis koin keramat.

c) Peningkatan level karakter musuh khususnya karakter bos.

4) Objectives

Tujuan dari game ini adalah mengalahkan musuh di setiap permainan untuk memenangkan game. Hal ini berlaku di mode Campaign dan Challenge.

5) Play Flow

Game ini menyediakan beberapa aksi yang dapat dilakukan oleh pemain yaitu:

a) Menempatkan koin di semua bidang di arena permainan.

b) Bergerak dalam arena Mul-mulan ke kanan, kiri, atas, bawah, diagonal.

c) Menyerang secara bergiliran dengan musuh.

d) Menggunakan kekuatan spesial dari koin keramat untuk menyerang musuh. 
6) Physics

Elemen fisik dalam game ini antara lain:

a) Karakter pemain tampil secara visual 2D, dalam permainan diwakili pergerakan koin dalam satu tampilan in-game, non scrolling.

b) Gerakan koin berpindah tempat dari satu bidang ke bidang lain dalam arena dengan bergerak ke kanan, ke kiri, ke atas, ke bawah atau secara diagonal.

c) Karakter dalam permainan bergantian dalam menempatkan koin dan bergerak sesuai bidang yang ditunjuk pemain.

d) Koin baik milik pemain maupun musuh tidak melawan saat diserang kecuali memiliki kekuatan spesial dari koin keramat. Dapat menyerang balik saat tiba giliran.

e) Koin keramat aktif dengan mengorbankan koin di arena dan hanya dapat digunakan sekalli.

7) Objects

Pemain dapat berinteraksi dengan objek yang tersedia dalam game, baik dalam tampilan menu hingga in-game. Interaksi yang dilakukan oleh pemain adalah dengan mentouch pada objek yang diinginkan. Objek di sini berupa tombol dalam tampilan GUI dan koin karakter. Pemain juga dapat mengetahui status karakter game dalam HUD yaitu meliputi;

a) Coin bar; bar yang menunjukkan jumlah dan jenis koin.

b) Dialog scene; panel kecil yang memperlihatkan dialog antar karakter selama permainan.

8) Economy

Keberadaan koin keramat dalam game menjadi sumber daya bagi pemain untuk memudahkan memenangkan permainan. Hal ini dikarenakan keberadaannya di dalam game hanya sebagai reward setiap memenangkan sebuah level.

9) Artificial Intelligence

Kecerdasan buatan diberikan pada penempatan koin oleh karakter lawan.

a) Koin ditempatkan pada bidang yang berdekatan dengan koin yang ada setiap gilirannya dan berusaha menempatkan diri di satu baris.

b) Koin mendeteksi posisi koin lawan yang memiliki penempatan sebaris baik vertikal, horisontal, maupun diagonal, kemudian mengisi di salah satu baris tersebut.

c) Koin dapat bergerak random dalam jangkauan bidang segiempat dari posisi koin lawan yang ada di arena tetapi memilih baris yang telah ada koin yang sejenis miliknya.

d) Saat jumlah koin di arena lebih sedikit dari koin lawan setelah giliran kelima, koin keramat dapat dimunculkan dengan mengorbankan pion di arena.

e) Kekuatan spesial koin keramat menyerang baris yang terdiri 2 koin lawan. 
GDD dibuat dalam sebuah dokumen buku yang menjadi dasar bagi visual artist, game artist, hingga programmer dalam mewujudkannya menjadi sebuah produksi game.

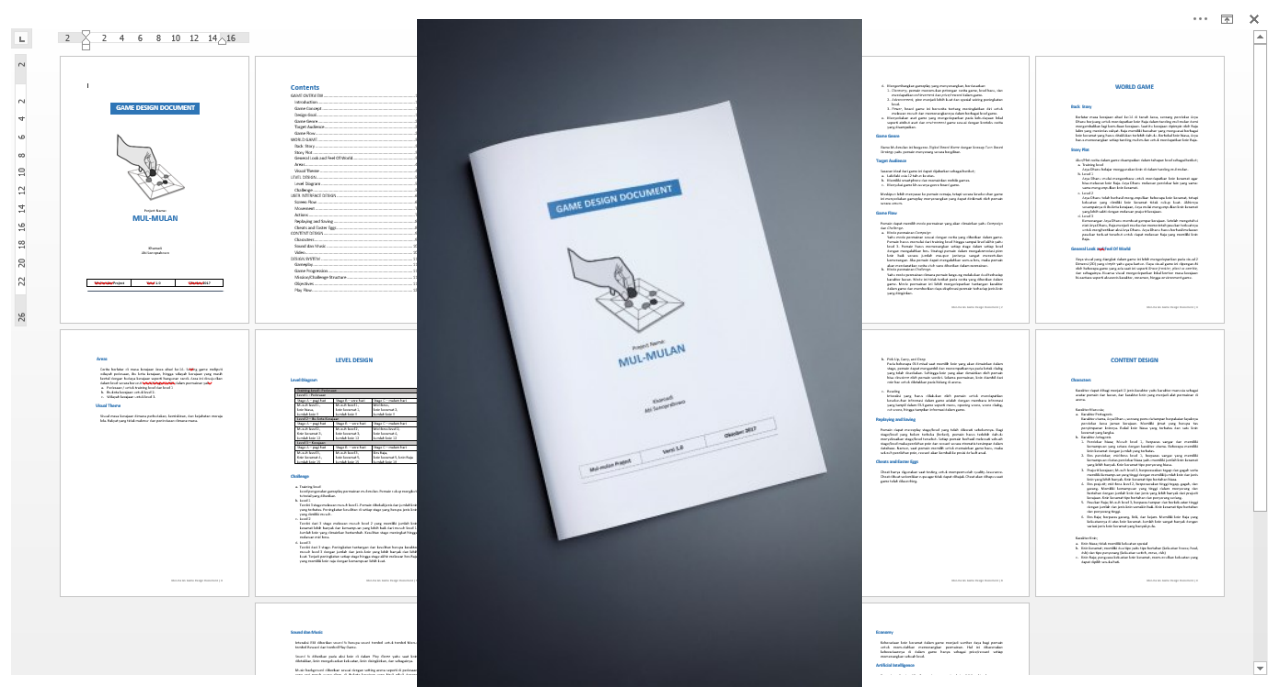

Gambar 3. Preview buku GDD Permainan Mul-mulan

[Sumber: Khamadi \& Abi Senoprabowo, 2017]

\section{KESIMPULAN}

Berdasarkan paparan hasil dan pembahasan didapatkan kesimpulan sebagai berikut:

a. Permainan Mul-mulan menjadi penting bagi anak untuk menumbuhkan kebanggaan berbudaya tradisi meskipun keberadaannya kian terpinggirkan.

b. Waktu bermain anak dan upaya pelestarian permainan Mul-mulan dapat berjalan beriringan dengan membawa permainan Mul-mulan ke dalam permainan digital yang memiliki nilai keunggulan menarik, interaktif, mudah diakses, dan dapat dimainkan sendiri tanpa harus mencari lawan bermain.

c. Adaptasi permainan Mul-mulan ke dalam permainan digital tetap harus mempertahankan elemen Concept, Icon, dan Shape dimana dalam elemen-elemen tersebut terkandung nilai budaya khas yang dimiliki permainan Mul-mulan.

d. Perancangan konsep permainan digital Mul-mulan menambahkan elemen sumber daya dan cerita yang tidak dijumpai di permainan Mul-mulan tradisional.

e. Perancangan GDD menjadi panduan dasar yang sangat penting dalam pembuatan game digital Mul-mulan. Hal ini dikarenakan game adaptasi dari tradisional ke digital dapat terdeskripsi secara detail dan menjaga jika ada elemen-elemen budaya yang seharusnya muncul menjadi hilang di saat pembuatan game.

\section{PENGHARGAAN}

Apresiasi setinggi-tingginya diberikan kepada Kementrian Riset, Teknologi dan Pendidikan Tinggi Indonesia yang telah memberikan dukungan penuh berupa dana penelitian dosen pemula tahun 2017. 


\section{DAFTAR PUSTAKA}

Adams, E. 2010. Fundamentals of Game Design 2nd ed. Berkeley: New Riders.

Dharmamulja, S. 2005. Permainan Tradisional Jawa. Yogyakarta: Kepel Press.

Fullerton, T. et all. 2013. Game Design Workshop : a Playcentric Approach to Creating Innovative Games, Third Edition. Burlington: CRC Press.

Handayani, P. P., M.Suyanto, \& Al Fatta, H. 2015. Perancangan Game Design Document Serious Game Permainan Tradisional Angklek Sleman Yogyakarta. Seminar Nasional Informatika 2015, 1, 1-7.

Khamadi, K., \& Senoprabowo, A. 2017. Adaptasi Permainan Papan Tradisional ke dalam Permainan Digital dengan Pendekatan Atumics: Studi Kasus Permainan MulMulan. In Seminar Nasional Seni dan Desain 2017 (Vol. 2, pp. 386-393). Surabaya: State University of Surabaya.

Khamadi \& Senoprabowo, A. 2016. Model Adaptasi Permainan Papan Tradisional Macanan Ke Dalam Perancangan Permainan Digital. Andharupa, Jurnal Desain Komunikasi Visual \& Multimedia, 2(2), 167-180.

Nugraha, A. 2012. Transforming Tradition : a Method for Maintaining Tradition in a Craft and Design Context. Helsinki: Aalto University, School of Arts, Design and Architecture.

Pulsipher, L. 2012. Game Design: How to Create Video and Tabletop Games, Start to Finish. McFarland \& Company, Inc., Publishers. 